\title{
THE EFFECTS OF PREVIOUS ADVERSITY, HAPPINESS AND RELIGIOUS FAITH IN ENHANCING UNIVERSITY STUDENTS' RESILIENCE TO THE COVID-19 PANDEMIC
}

\author{
Getrude C. Ah Gang, Chua Bee Seok, \& Carmella E. Ading \\ Faculty of Psychology and Education, University Malaysia Sabah (Malaysia)
}

\begin{abstract}
The start of 2020 marked a fresh beginning when people moved forward with new resolutions, all hoping for the best in their career, family, relationships, and academic pursuits. All those wishes were disrupted, however, by the Covid-19 pandemic, which has especially affected university students regarding their academic goals. The new learning norms that were adopted in universities to contain the spread of the pandemic have caused worry, anxiety, and stress in many students. To deal with these unexpected circumstances, university students must augment their inner strengths to enhance their resiliency during the Covid-19 pandemic. To better understand the situation, this study examined previous adversity, happiness and religious faith that were predicted to enhance students' resiliency. There were 415 university students in Sabah, Malaysia participated in the study. The mean age was 21.96 years $(\mathrm{SD}=4.08)$. Among the participants, there were 330 females $(79.50 \%), 84$ males $(20.20 \%)$ and one person $(0.2 \%)$ who did not disclose a gender. The study found that students who were happier and stronger in religious faith tended to be more resilient while the experience of many previous adversities had a significant negative effect on students' resiliency. Based on these findings, we hope that more university programs will be devised to elevate students' happiness, build stronger faith and offering psychological programs for students who have experienced many previous difficulties.
\end{abstract}

Keywords: Resiliency, religious faith, happiness, past-life adversity.

\section{Introduction}

The spread of the coronavirus which was marked in Wuhan, China was not only caused a great worry and panic to the Wuhan community but people around the globe. This when coronavirus cases were first reported by the World Health Organisation (WHO) that occurred in Japan, South Korea, and Thailand (Taylor, 2020). To prevent the cases from getting increased, many governments of the affected country have implemented the lockdown as to control and to flatten the coronavirus cases, including in Sabah, Malaysia. Many schools and universities were temporarily closed and replaced with the fully online and distance learning. In Malaysia, the first phase of lockdown was marked on the 18 March until 01 April 2020 and extended to other phases because of the increasing coronavirus cases. This has caused concern among the governments and society of the economic, social, and health downturn. Many well-planned activities were disrupted and need to be adjusted and this also affected local and private university students who were amid their study.

During the pandemic, many students struggle in adjusting their new studying norms from face-to-face learning to fully online and distance learning. Some students might face difficulty in joining the online teaching due to the poor internet connection or lack of infrastructure such as electricity particularly students in the interior place. This may cause worry, anxiety, and stress because they might miss their subject learning and the online exam. In the flip side, they have more time for reading, completing their academic tasks and involving in personal in-door activities and these may help to uplift their positive feelings such as happiness. According to Tyagi, Gaur \& Sharma (2020), most students are happy while staying at home because they have adequate time for themselves and these can help them to keep their emotions in control. For students who were stayed on-campus, they have more time to focus on their study and able to follow the online teaching because of good internet connection provided by the university. 
Continuous intangible and tangible support from the university and government may also help to regain students' happiness during the lockdown. For instance, the Sabah government provide tangible assistance to 40 public and private higher learning institutions in Sabah (Borneo Post, April 16, 2020). Hence, happiness that reflected on students' may help to lift their resiliency in facing with coronavirus challenges. Past studies (e.g., Aboalshamat et. al., 2018; Kirmani, Sharma, Anas \& Shanam,2015; Tyagi et al., 2020) revealed that there is an effect of resiliency on happiness. Positive emotions are essential not only for producing durable happiness, but also for bolstering coping and resilience in the face of adversity (Lyubomirskt \& Della Porta, 2008).

In terms of religious beliefs, people who are devoted to their religious faith are happier, healthier, and have more coping resources than those for whom religion and spirituality are less important (Patrick \& Kinney,2003). In addition, the strong spiritual beliefs may lead to higher levels of psychological well-being (Kumar \& Singh, 2014). Besides happiness and religious faith, past-life adversity is also one of the factors which can elevate students' resiliency. Previous studies (e.g., Brett \& McKay, 2020; Gartland et al.,2019) revealed that students' who experiences of previous difficulties such as during childhood and teenagers may allow them to be more resilient by developing independence and determination. This showed that past-life difficulties can help the person to regain and move forward for a better way.

\subsection{Literature review}

Some people believe that they cannot choose to be happy and they cannot influence their own emotion. This belief however can become a self-fulfilling prophesy, helping doom them to unhappiness (Stevens,2010). However, when we think positively, we tend to perceive things in colours and may spark happiness in our life. This happy moment may help people to be in control and be more mindfulness which lead to strong resiliency in facing life difficulties. When we feel happy, we tend to think positively and approaching life's challenges with a positive outlook as stated in past studies (e.g.,Cosmas, 2020; Lower, 2014). Besides happiness, religion is also used as a tool to overcome any life difficulties. People who held a religion regardless any faith backgrounds tend to rely on their spirituality beliefs when facing any kind of circumstances. This may help them to search the meaning and understanding of things that happen surround them such as the corovirus pandemic. Pirustinsky, Cherniak and Rosmarin (2020) stated that religion can stands as a coping mechanism in dealing with life stress. By engaging in religious activities such as praying daily, perceiving religion as an important source of happiness, comfort, meaning, and life purpose may strengthen students' faith and resiliency. The past-life adversity also contributes to strong resiliency resilient participants with more experiences of adversity and stress showed higher well-being than those with fewer stressful experiences. Resilient people are those who learn to move past obstacles and challenges in healthy way (Cheetham-Blake et al., 2019; Hildon et al.,2008). They also learn how to set themselves back on even ground after a stressful event (Riopel, 2020). A study by Newcomb et al. (2019) focused on 265 undergraduate students in Queensland, Australia and reported that students who experience childhood adversity tend to develop independence and determination, which in turn led to the development of resilience, giving them greater ability to cope with the stresses of university courses. The preceding argument of past-life adversity shows that students who experienced life difficulties in the past tend to have strong resiliency when dealing with any difficult circumstances.

\section{Design}

In this study, participants were recruited based on purposive sampling and snowball sampling which focuses on university students both local and university students in Sabah, Malaysia. The purposive sample is a non-probability sample that is selected based on characteristics of a population and the objective of the study (Crossman, 2020).

\section{Objectives}

Based on the three preceding factors (i.e., happiness, religious faith \& past-life adversity), we predicted that students who scored higher level of happiness, strong religious faith, and experienced past life difficulties (e.g., academic, financial, and family problems) might be less vulnerable when facing difficulties during the coronavirus lockdown and pandemic. This is because each of this factor contributed to students' resiliency. These three factors were thoroughly examined and discussed in this paper. 


\section{Methodology}

Amid the coronavirus, the most convenient and safety strategy in conducting data collection is by using a Google form survey. Participants were invited to join in this study by sending them the Google form survey link through various social media platforms. In addition, we also use snow-ball strategy by requesting students who were already participated in this study to share the survey link to their friends. This may help to involve more local and private students to participate in this study. A set of questionnaires consisting of demographic profile and four scales (i.e., resiliency, religious faith, happiness, \& past-life adversity) were used to gather data. Demographic Profiles to gather data on participants' demographic information. Brief Resilient Coping Scale (Sinclair \& Wallston, 2004); to measure students' resiliency coping skills and the response rate from 1- 'does not describe me at all' to 5- 'does describe me very well.' The sample items for this scale were 'I look for creative ways to alter difficult situations,' and I actively look for ways to replace the losses I encounter in life'. Subjective Happiness Scale (Lyubomirsky \& Lepper,1999); to measure students' happiness during the three phases of the coronavirus lockdown. The sample items were "In general I consider myself as..." and 'Compared to most of my peers, I consider myself as....' The scale response ranged from 1- 'not a very happy person' to 7- 'a very happy person'. Religious Faith Scale (Plante \& Boccaccini,2007); to measure participants' religious faith by asking participants to rate the level of agreement for each item based on the 5-point Likert-type scale, ranging from 1- 'strongly disagree to 5- 'strongly agree.' The sample items were 'I look to my faith as the source of inspiration,' and 'I look to my faith as a source of comfort.'

Past-life Adversities Scale (adapted from Boparai et al.’s 2017 \& Felitti et al.'s 1998), This scale that examined the challenges participants' face in daily life such as financial, familial, relationship, and academic challenges. The response scale is binary, with 1- 'yes' and 2- 'no.' The internal consistency for each scale in this study ranged from .60-.95.

\subsection{Results}

A total of 415 public and private university students participated in this study. The mean age was 21.96 ( $\mathrm{SD}=4.08)$. There were 330 females $(79.50 \%), 84$ males $(20.20 \%)$, and $1(0.3 \%)$ who did not disclose a gender. The study found that students who were happier and stronger in religious faith tended to be more resilient while the experience of many previous adversities had a significant negative effect on students' resiliency. The simple regression test for the alternate hypothesis showed that there are positive, significant effects of happiness on students' resiliency $\left(\beta=.24, \mathrm{t}_{1.414}=4.96, \mathrm{p}=.00\right)$. The happier the students, the higher their resilience. Happiness contributed $5.6 \%$ to the variance of resiliency. Religious faith contributed $6.4 \%$ to the variance of resiliency $\left(\beta=.26, \mathrm{t}_{1.414}=5.43, \mathrm{p}=.00\right)$. These two findings demonstrate that students who reported being happier and having stronger religious faith tended to show high resilience. In contrast, students who experienced more past-life adversity (e.g., felt unsupported or unloved, lived with divorced parents or dealt with family members with social problems) tended to have lower resiliency. The study showed that past-life adversity showed significant effect on resiliency $\left(\beta=-.11, \mathrm{t}_{1.141}, \mathrm{t}=-2.31, \mathrm{p}=.02\right)$ which contributed $1.3 \%$ on the variance resiliency.

\section{Discussion}

The study revealed that participants who were happier showed higher in resiliency. This happy feeling could be retrieved from various sources during the pandemic such as gain more time to complete their academic tasks and other personal activities. This revealed in Tyagi et al.'s (2020) study that most students actually happy while staying at home. This is because they have more time to read and completed their academic tasks. All these can help them to keep their emotions in control and be more focused on their academic. In addition, by staying at home, they will be less worry of being infected. This in turn can help to strengthen students' resiliency when dealing with huge changes like those they experienced during the pandemic. Being happy is not only feels good, but it is also associated with successful outcomes in life. However, we cannot deny, some students might find it difficult to feel happy, especially during the pandemic. In times of stress and uncertainty, people easy to get panic and become irrational. However, in order to defeat Covid-19, it is essential to remain positive, optimistic and collaborative; choosing to be happy will support all of that (Al Atabi, 2020). In this study, stronger religious faith may elevate students' resiliency during the three phases of the coronavirus lockdown. This is in line with past studies (Agaibi, 2018; Rahmati et al., 2017) that resiliency can be strengthened by religious faith. Religious faith is a powerful source of hope, meaning, peace, comfort, and forgiveness for oneself (Brewer-Smyth \& Koenig, 2014). Resilience appears to be an important concept in religion, and religion appears to correlate with an individual's resilience (Lower, 2014). This might be one of the reasons that contributed to resiliency. Most participants in this study recognized religion and spirituality to be an important part of life. Strong religious 
faith and spirituality are associated with increased coping mechanisms, greater resilience to stress, optimistic life orientations, greater perceived social support, and lower levels of anxiety (Pardini et al., 2001). In this study, students' past life adversity showed significant and negative effect on students' resiliency. This in line with previous studies (e.g., Newcomb et al. (2019) that past life difficulties contribute to students' resiliency. A study by Newcomb et al. (2019) reported that students' experiences of childhood adversity allowed them to develop independence and determination. This will bring to the development of resilience and have greater ability to cope with any unexpected events among university students.

\section{Conclusions}

The study's findings showed that each of the three factors can help students regain their resiliency in dealing with unforeseen challenges during the coronavirus pandemic. This study gives us a glimpse of hope helps us reflect on how students' inner peace and strength (i.e., happiness and religious faith) need to be understood as resources to deliver psychological assistance during the pandemic apart from external supports. This may help them be more resilient when facing any difficulties related to the pandemic and any unexpected events in the future. Resilience is a set of skills that can be taught and learned, it is not based on genetic. It is the ability to withstand, bounce back and grow in the face of stressors and changing demands (Precker,2020). The coronavirus pandemic that caused uncertainty and mental breakdown for university students around the globe may offer students the chance to reflect on the importance of happiness and religious faith while coping with coronavirus hardships. All these factors may help them to cope with life challenges and grow in faith effectively.

\section{Acknowledgements}

We convey our gratitude to the Centre of Research and Innovation, UMS for the COVID-19 Research Grant 2020 (SDK0228-2020) and to all the participants who were involved in this study during the coronavirus pandemic.

\section{References}

Aboalshamat,K.T., Alsiyud, A.O.,Al-Sayed, R.A, Alreddadi,R.S., Faqiehi, S.S., \& Almehmadi,S.A.(2018). The Relationship between Resilience, Happiness, and Life Satisfaction in Dental and Medical Students in Jeddah, Saudi Arabia, Nigerian Journal of Clinical Practice,21,8,1-7

Agaibi, C.E. (2018). Resilience: A versatile concept from Biblical to modern times, The Journal of Happiness \& Well-Being, 6(1), 33-48 33

Al Atabi, M. (March 19, 2020). Choosing to be happy can help during Covid-19 outbreak, https://www.nst.commy/opinion/columnists/2020/03/576141/choosing-be-happy-can-help-duringcovid-19-outbreak

Anastasova, R. (2014). Understanding the Role of Religion in Coping after Trauma: Resilience, Post-traumatic Growth and Difference in Coping Mechanisms, Master Thesis, Tilburg University

Boparai, S.P., Marie, T., Aguayo, E.., Brooks, J., \& Juarez, E. (2017). Adversity and academic performance among adolescent youth: A community-based participatory research study, Journal of Adolesecent and Family Health, 8, 1, 1-33

Borneo Post online. (April 16, 2020).RM930,680 aid for 23,267 students, https://www.theborneopost.com/2020/04/16/rm930680-aid-for-23267-students/

Brewer-Smyth, K., \& Koenig, H.G. (2014) Could Spirituality and Religion Promote Stress Resilience in Survivors of Childhood Trauma?, Issues in Mental Health Nursing, 35,4, 251-256., DOI: $10.3109 / 01612840.2013 .873101$

Cheetham-Blake, T.J., Turner-Cobb J.M., Family, H.E., \& Turner, J. E. (2019). Resilience characteristics and prior life stress determine anticipatory response to acute social stress in children aged 7-11 years, Br, J.Health Psychology, 24,2,282-297, doi: 10.1111/bjhp.12353. Epub 2019 Jan 13.

Cosmas, G. (2020). Psychological Support in Uplifting University Students ${ }^{\text {ee }}$ Happiness in Fighting the Coronavirus Lockdown.Postmodern Openings, 11(2), 31-42. https://doi.org/10.18662/po/11.2/155

Crossman, A. (2020). Understanding purposive sampling:An overview of the method and its applications, thoughtco.com/purposive-sampling-3026727 
Felitti,V. J., Anda, R.F., Nordenberg, D., Williamson, D .F., Spitz, A. M., Edwards,V., Koss, M.P., Marks,J. S. (1998). Relationship of childhood abuse and household dysfunction to many of the leading causes of death in adults: The adverse Childhood Experiences (ACE) study, American Journal of Preventive Medicine, 14,4,245-258

Gartland D., Riggs E., Muyeen S., Giallo, R., Afifi, T. O., MacMillan, H., Herrman, H., Bulford, E., \& Brown, S. J. (2019). What factors are associated with resilient outcomes in children exposed to social adversity? A systematic review. BMJ Open,9,1-14.doi:10.1136/ bmjopen-2018-024870

Hildon, Z., Smith,G., Netuveli,G., \& Blane,D.(2008).Sociology of Health \& Illness,30,5,726-740, doi: 10.1111/j.1467-9566.2008.01087.x

Kirmani, M. N., Sharma, P., Anas, M., \& Sanam, R. (2015). Hope, Resilience and Subjective Well-being among college going Adolescent Girls, International Journal of Humanities \& Social Science Studies, II, I, 262-270

Koenig, H. G. (2007). Spirituality and depression: A look at the evidence. Southern Medical Journal, 100, 737-739.

Kumar, A. U. \& Singh, R. (2014). Resilience and Spirituality as Predictors of Psychological Well-Being among University Students. Journal of Psychosocial Research, 9(2), 227-235.

Lower, K. (2014). Understanding resilience and happiness among college students, thesis, Middle Tennessee State University https://jewlscholar.mtsu.edu/bitstream/handle/mtsu/3633/Lower_mtsu_0170N_10227.pdf?sequenc $\mathrm{e}=1$

Lyubomirsky, S., \& Della Porta, M. (2008). Boosting happiness, buttressing resilience: Results from cognitive and behavioral interventions. In J. W. Reich, A. J. Zautra, \& J. Hall (Eds.) (pp.450-464), Handbook of adult resilience: Concepts, methods, and applications. Guilford Press.

Lyubomirsky, S., \& Lepper, H. S. (1999). A measure of subjective happiness:Preliminary reliability and construct validation. Social Indicators Research, 46(2),137-155

Newcomb, M, Judith Burtonb, J., \& Edwards, N. (2019). Student Constructions of Resilience: Understanding the Role of Childhood Adversity Michelle. Australian Social Work, 72(2), 166-178. https://doi.org/10.1080/0312407X.2018.1550521

Patrick J. H. \& Kinney J M. Why believe? The effects of religious beliefs on emotional well being. In: McFadden SH, Brennan M, Patrick JH, editors. New directions in the study of late life religiousness and spirituality. Haworth Press; Binghamton, NY: 2003. pp. 153-170.

Pirutinsky, S., Cherniak, A. D., \& Rosmarin, D. H. (2020). COVID-19, Mental Health, and Religious Coping Among American Orthodox Jews. Journal of religion and health, 59(5), 2288-2301.

Plante, T.G., \& Boccaccini, M. T. (2007). The Santa Clara Strength of Religious Faith Questionnaire, Pastoral Psychology, 4, 5,375-387 DOI: 10.1007/BF02230993

Precker, M. (September 9, 2020). In these tough times, focus on resilience, https://www.heart.org/en/news/2020/09/09/in-these-tough-times-focus-on-resilience

Rahmati M, Khaledi B, Salari N, Bazrafshan M, Haydarian A.(2017). The Effects of Religious and Spiritual Interventions on the Resilience of Family Members of Patients in the ICU, Shiraz E-Med Journal, 18(11):e13007. doi: 10.5812/semj.13007

Sinclair, V. G., \& Wallston, K.A. (2004). The development and psychometric evaluation of the Brief Resilient Coping Scale. Assessment, 11 (1), 94-101. https://www.ncbi.nlm. nih.gov/pubmed/14994958

Stevens, T. G. (2010). You can chose to be happy:Rise above anxiety, anger and depression ( $2^{\text {nd }}$ Ed.). Wheeler-Sutton Publishing co.

Taylor, D. B. (August, 2016). A timeline for the coronavirus pandemic. The New York Times, nytimes.com/article/coronavirus-timeline.html

Tyagi, K., Gaur, G., \& Sharma, M. (2020). Readership among college students during COVID19 lockdown: A Cross-Sectional Survey in a Northern City of India. Indian Journal of Preventive \& Social Medicine, 51(2), 72-76. 